\title{
PENGARUH PENAMBAHAN KOMPOS PADA TANAH UNTUK MENGURANGI GENANGAN DI KELURAHAN BULAK, KECAMATAN KENJERAN, KOTA SURABAYA
}

\author{
Sulistiya Nengse \\ Program Studi Teknik Lingkungan, Universitas Islam Negeri Sunan Ampel, Jl. Jend. A. Yani 117 Surabaya \\ Email: sulistiya703@gmail.com
}

\begin{abstract}
ABSTRAK
Genangan di Kelurahan Bulak, Kecamatan Kenjeran, Kota Surabaya bukan disebabkan meluapnya sungai, namun lebih dikarenakan tingginya intensitas hujan lokal yang diperparah dengan buruknya manajemen drainase kota, disamping itu kontur wilayah Kelurahan Bulak merupakan permukaan yang relatif datar dengan jenis tanah yang mempunyai resapan rendah. Upaya yang telah dilakukan oleh Pemerintah Kota Surabaya dalam mengantisipasi genangan yakni membangun rumah-rumah pompa banjir, membuat gorong-gorong, biopori, membersihkan saluran dari timbunan sampah, dan melakukan pengerukan sedimen di bozem yang merupakan tempat penampungan air hujan sementara sebelum dibuang ke laut. Namun saat ini semua upaya tersebut belum cukup membuahkan hasil dalam menangani genangan air. Salah satu cara yang efektif untuk menangani genangan air adalah memodifikasi lapisan tanah permukaan dengan menambahkan pupuk kompos dedaunan dan ranting. Penelitian ini untuk menentukan pengaruh jumlah kompos yang ditambahkan pada tanah terhadap peningkatan resapan dan reduksi lama genangan banjir. Penelitian dilakukan menggunakan metode pencampuran tanah dan kompos pada skala laboratorium. Penelitian ini menggunakan variabel penelitian jumlah kompos yang ditambahkan. Parameter yang dianalisis adalah jenis tanah dan laju resapan tanah (f). Hasil penelitian menunjukkan penambahan kompos daun dan ranting sebesar $15 \%$ ke tanah dapat meningkatkan resapan dari $0,298 \mathrm{~cm} /$ menit menjadi $0,904 \mathrm{~cm} / \mathrm{menit}$ dan penambahan kompos daun dan ranting 35\% dapat meningkatkan resapan menjadi 1,099 cm/menit.
\end{abstract}

Kata kunci: genangan, resapan, tanah, kompos.

\section{PENDAHULUAN}

Banjir di Kelurahan Bulak, Kecamatan Kenjeran, Kota Surabaya bukan disebabkan meluapnya sungai, namun lebih dikarenakan tingginya intensitas hujan lokal yang diperparah dengan buruknya manajemen drainase kota, disamping itu kontur wilayah Kelurahan Bulak merupakan permukaan yang relatif datar dengan jenis tanah yang mempunyai resapan rendah. Meskipun ancaman banjir di Kelurahan Bulak tidak begitu parah, namun antisipasi terhadap terjadinya banjir perlu dilakukan. Hal ini dikarenakan curah hujan di Kota Surabaya terbilang tinggi sehingga masih ada kawasan yang tergenang air saat musim hujan.

Upaya yang telah dilakukan oleh Pemerintah Kota Surabaya dalam mengantisipasi banjir yakni membangun rumah-rumah pompa banjir, membuat gorong-gorong, biopori, membersihkan saluran dari timbunan sampah, dan melakukan pengerukan sedimen di bozem yang merupakan tempat penampungan air hujan sementara sebelum dibuang ke laut. Namun saat ini semua upaya tersebut belum cukup membuahkan hasil dalam menangani genangan air.

Alternatif penanganan genangan air perlu dilakukan untuk mencapai kehidupan yang lebih nyaman. Salah satu cara yang efektif untuk menangani genangan air adalah memperbesar area resapan air dengan cara meningkatkan resapan tanah. Mengingat tanah asli di Kelurahan Bulak mempunyai laju peresapan yang rendah maka perlu dilakukan modifikasi terhadap tanah permukaan tersebut, sehingga laju peresapan atau infiltrasinya meningkat. Penelitian ini melakukan modifikasi terhadap lapisan tanah permukaan dengan cara menambahkan pupuk kompos dedaunan dan ranting.

Menurut Murbandono (2009), pupuk kompos diketahui dapat meningkatkan porositas tanah dan memperbesar kemampuan tanah menampung air. Struktur tanah lempung dapat diperbaiki dengan penambahan kompos agar dapat menyimpan air lebih lama. Jurnal ini menyajikan hasil penelitian terkait kemampuan campuran tanah 
dan kompos dalam meningkatkan resapan air pada daerah genangan/rawan banjir di Kelurahan Bulak, Kecamatan Kenjeran. Tujuan dari penelitian ini untuk menentukan pengaruh jumlah kompos yang ditambahkan pada tanah terhadap peningkatan resapan dan menentukan besar kemampuan campuran tanah dan kompos dalam mereduksi lama genangan banjir di daerah rawan genangan Kelurahan Bulak, Kecamatan Kenjeran.

\section{METODOLOGI PENELITIAN}

\section{Pengambilan Sampel}

Sampel diambil di tanah kosong yang masih berupa tanah asli dan belum pernah diurug di daerah Jalan Kyai Tambak Deres Kelurahan Bulak, Kecamatan Kenjeran, Kota Surabaya. Pengambilan sampel di lokasi ini didasarkan pada data dari Dinas Pekerjaan Umum Bina Marga dan Pematusan Kota Surabaya Tahun 2012. Berdasarkan data tersebut luas area genangan di daerah Jalan Kyai Tambak Deres Kelurahan Bulak adalah 0,45 ha, tinggi genangan $40 \mathrm{~cm}$, dan lama genangan 120 menit.

Sampel diambil dari tiga titik (titik 1, 2, dan 3) yang mana jarak antara masing-masing adalah 3 meter. Masing-masing titik diambil dua sampel, yaitu sampel tanah di permukaan dan sampel tanah pada kedalaman $30 \mathrm{~cm}$ dari permukaan. Total sampel tanah sebanyak 6 sampel. Sampel diambil antara tanah permukaan hingga kedalaman $30 \mathrm{~cm}$ karena diprediksi sebelum $30 \mathrm{~cm}$ belum terdapat air tanah sehingga tanah tidak jenuh dan mudah dianalisis. Selain itu tanah pada kedalaman $30 \mathrm{~cm}$ lebih mudah dalam pengaplikasian karena tidak perlu menggunakan alat berat. Tanah pada kedalaman ini masih berupa top soil. Sketsa titik pengambilan sampel seperti pada Gambar 1. Kondisi sampel tanah dilihat secara visual tercantum pada Tabel 1.

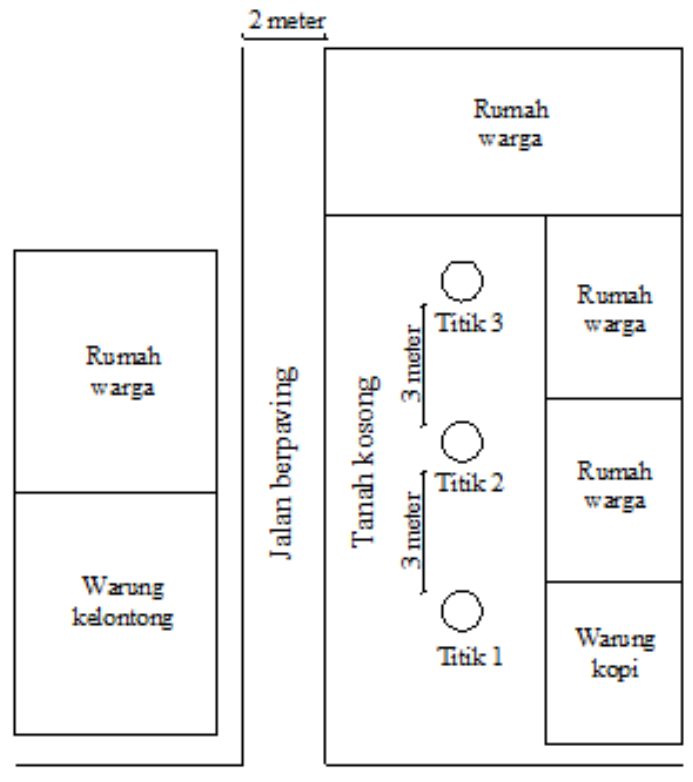

Jalan Kyai Tambak Deres

Gambar 1 Sketsa titik pengambilan sampel tanah

Tabel 1 Kondisi sampel tanah

\begin{tabular}{clll}
\hline Sampel & $\begin{array}{c}\text { Lokasi } \\
\text { pengambilan }\end{array}$ & \multicolumn{2}{c}{ Kondisi tanah tampak visual } \\
\hline 1 & Titik 1 & Permukaan & Berpasir dan gembur \\
2 & (depan) & kedalaman $30 \mathrm{~cm}$ & Berpasir dan basah \\
3 & Titik 2 & Permukaan & Berpasir dan gembur \\
4 & (tengah) & kedalaman $30 \mathrm{~cm}$ & Berpasir dan basah \\
5 & Titik 3 & Permukaan & Berpasir dan gembur \\
6 & (belakang) & kedalaman $30 \mathrm{~cm}$ & Liat dan basah \\
\hline
\end{tabular}




\section{Penyiapan Campuran Tanah dan Kompos}

Kompos yang digunakan berasal dari daun dan ranting diambil dari Rumah Kompos Bratang. Campuran tanah dan kompos dengan berbagai variasi disajikan pada Tabel 2. Adanya variasi tanah asli 100\% dan kompos $100 \%$ digunakan sebagai variabel kontrol terhadap variasi campuran lainnya. Sebelum dicampurkan, tanah asli terlebih dahulu dibentuk remah-remah agar tidak menggumpal dan lebih mudah dalam pencampuran dengan kompos. Begitupun dengan tanah asli 100\%, sebelum dilakukan analisis laboratorium tanah asli dibuat remah terlebih dahulu. Pencampuran tanah dan kompos menggunakan perbandingan berat, sebagai contoh: dalam pembuatan campuran tanah $85 \%$ dan kompos $15 \%$ diambil tanah asli sebanyak 850 gram kemudian dicampurkan kompos sebanyak 150 gram.

Tabel 2. Variasi campuran tanah dan kompos

\begin{tabular}{cllc}
\hline No. & Variasi campuran & Komposisi & Prosentase \\
\hline 1. & Tanah asli & Tanah asli & $100 \%$ \\
2. & Kompos & Kompos & $100 \%$ \\
3. & Campuran 1 & Tanah asli & $85 \%$ \\
& & Kompos & $15 \%$ \\
4. & Campuran 2 & Tanah asli & $75 \%$ \\
& & Kompos & $25 \%$ \\
5. & Campuran 3 & Tanah asli & $65 \%$ \\
& & Kompos & $35 \%$ \\
\hline
\end{tabular}

\section{Pemeriksaan Sampel Tanah}

Pemeriksaan sampel tanah meliputi analisis laboratorium sebagai berikut:

- Analisis ayakan tanah asli

Analisis ayakan bertujuan untuk menentukan jenis tanah yang dilakukan dengan metode saringan ayakan.

- Analisis resapan

Analisis resapan menggunakan alat dari tabung transparan berdiameter $6 \mathrm{~cm}$ dan tinggi $10 \mathrm{~cm}$ yang dirangkai seperti sketsa pada Gambar 2. Perhitungan laju resapan menggunakan rumus infiltrasi (RSNI T-06-2004) yaitu:

$$
f=\frac{\Delta V}{A \times \Delta t}
$$

dengan $f=$ laju infiltrasi/resapan ( $\mathrm{cm} /$ jam), $\Delta V=$ volume air yang ditambahkan untuk menjaga muka air konstan tiap selang waktu $\left(\mathrm{cm}^{3}\right), A=$ luas bidang $\left(\mathrm{cm}^{2}\right)$, dan $\Delta t=$ selang waktu pengukuran (menit).

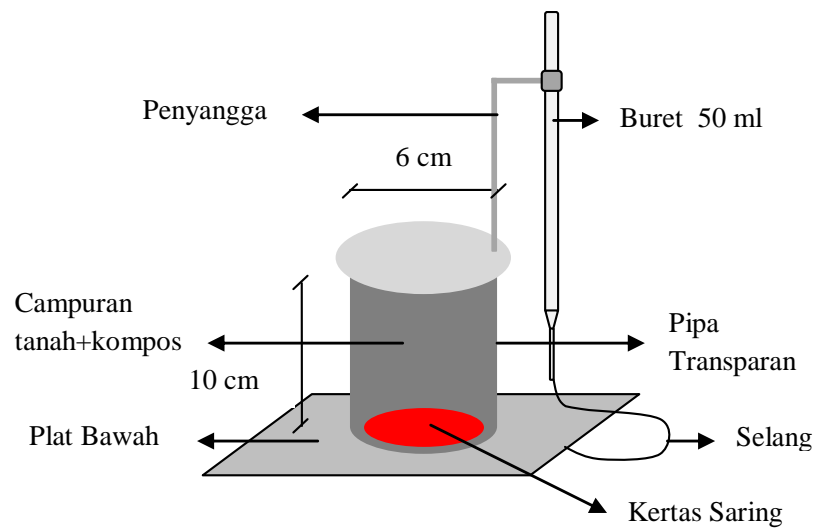

Gambar 2. Sketsa alat uji laju resapan 


\section{HASIL DAN PEMBAHASAN}

\section{Analisis Ayakan}

Analisis ayakan adalah mengayak contoh tanah melalui satu set ayakan dimana lubang-lubang ayakan tersebut makin kecil secara berurutan. analisis ayakan dilakukan untuk mengetahui tanah mana yang memiliki kondisi paling jelek untuk resapan, tanah yang memiliki resapan jelek adalah tanah yang banyak mengandung lempung. analisis ayakan ini mengikuti sni 03-3423-1990 ; astm d $422-90$ (1973). Analisis ayakan dilakukan terhadap seluruh sampel tanah yang berjumlah 6 sampel agar dapat diketahui jenis tanah dominan yang terkandung tanah tersebut. setiap sampel tanah diambil 500 gram untuk dilakukan analisis ayakan. hasil analisis ayakan menunjukkan bahwa sampel tanah yang memiliki komposisi lempung paling besar adalah sampel yang diambil pada titik ketiga kedalaman $30 \mathrm{~cm}$ dari permukaan, dimana komposisi lempung yang dikandung adalah 16,45\%. pengambilan sampel tanah berikutnya diambil pada titik pengambilan sampel nomer 6 ini, yaitu pada titik ketiga kedalaman $30 \mathrm{~cm}$ dari permukaan. hasil analisis ayakan sampel bisa dilihat pada tabel 3. Tanah yang diambil haruslah tanah undisturbed (tanah yang tidak terganggu) karena beberapa parameter yang dianalisiskan adalah kadar air dan berat volume tanah yang mana dalam penganalisisan parameter tersebut harus menggunakan tanah undisturbed. Cara pengambilan tanah undisturbed ini menggunakan tabung shelbi.

Tabel 3. Hasil ayakan sampel tanah pada titik ketiga kedalaman $30 \mathrm{~cm}$

\begin{tabular}{ccccc} 
Nomor Ayakan & Berat Tertahan (gram) & \% Tertahan & \% Komulatif & \% Lolos \\
\hline $2 "$ & 0 & 0 & 0 & 100 \\
$1 "$ & 21,00 & 4,20 & 4,20 & 95,80 \\
$3 / 4 "$ & 6,70 & 1,35 & 5,55 & 94,45 \\
$3 / 8 "$ & 24,70 & 4,95 & 10,50 & 89,50 \\
4 & 15,30 & 3,06 & 13,56 & 86,44 \\
10 & 25,30 & 5,06 & 18,62 & 81,38 \\
20 & 7,70 & 1,54 & 20,16 & 79,84 \\
40 & 17,80 & 3,55 & 23,71 & 76,29 \\
100 & 87,70 & 17,53 & 41,24 & 58,76 \\
200 & 45,40 & 9,08 & 50,32 & 49,68 \\
PAN & 248,40 & 49,68 & 100 & 0 \\
\hline
\end{tabular}

Dari data di atas dapat dibuat grafik (Gambar 3) dimana sumbu X atas adalah nomor ayakan, sumbu X bawah adalah diameter butiran, dan sumbu Y adalah prosentase lolos (Liu, 1981).

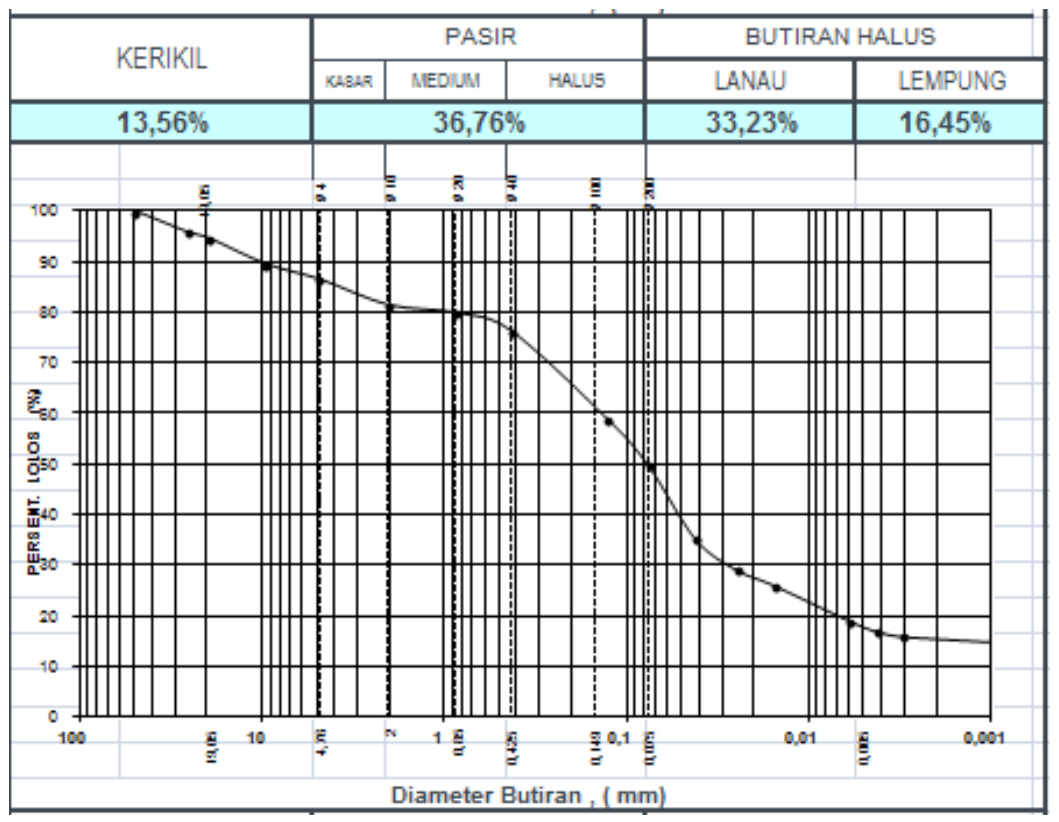

Gambar 3. Grafik hasil ayakan sampel 


\section{Laju Resapan}

Analisis laju resapan tanah dilakukan untuk mengetahui kemampuan campuran tanah dan kompos dalam meresapkan air. Analisis laju resapan tanah menggunakan alat dari pipa transparan dilengkapi dengan buret untuk mengukur banyaknya air yang meresap lalu dirangkai sedemikian rupa (Gambar 2) sehingga dapat diamati berapa banyak air yang dapat meresap ke dalam campuran tanah per satuan waktu. Perhitungan laju resapan menggunakan Persamaan (1). Berikut adalah contoh perhitungan laju resapan tanah asli:

Dari hasil analisis laboratorium didapatkan data sebagai berikut:

Luas permukaan tabung yang digunakan $\quad=1 / 4 \times \pi \times \mathrm{d}^{2}$

$$
\begin{aligned}
& =1 / 4 \times 3,14 \times 6,29^{2} \\
& =31,058 \mathrm{~cm}^{2} \\
& =140.400 \text { detik } \\
& =14,5 \mathrm{~cm}^{3} \\
& =6,29 \mathrm{~cm}
\end{aligned}
$$

Waktu yang dibutuhkan $(\Delta \mathrm{t})$

Volume air yang keluar $(\Delta \mathrm{V})$

\begin{tabular}{|c|c|c|c|c|c|c|c|}
\hline Campuran & $\begin{array}{c}\text { Waktu } \\
\text { yang } \\
\text { dibutuhkan }\end{array}$ & $\begin{array}{c}\text { Volume } \\
\text { air yang } \\
\text { keluar }\end{array}$ & $\begin{array}{c}\text { Luas } \\
\text { permukaan } \\
\text { tabung }\end{array}$ & $\begin{array}{l}\text { Kapasitas } \\
\text { Resapan }\end{array}$ & $\begin{array}{l}\text { Laju } \\
\text { resapan } \\
\text { (f) }\end{array}$ & $\begin{array}{c}\text { Laju } \\
\text { resapan (f) }\end{array}$ & $\begin{array}{c}\text { Laju } \\
\text { resapan } \\
\text { (f) }\end{array}$ \\
\hline & (detik) & $\left(\mathrm{cm}^{3}\right)$ & $\left(\mathrm{cm}^{2}\right)$ & $\left(\mathrm{m}^{3} / \mathbf{j a m}\right)$ & (cm/detik) & (cm/ menit) & $(\mathrm{cm} / \mathrm{jam})$ \\
\hline Tanah asli & 600 & 92,587 & 31,058 & $0,556 \times 10^{-3}$ & 0,005 & 0,298 & 17,887 \\
\hline Kompos & 75 & 129,478 & 31,058 & $6,215 \times 10^{-3}$ & 0,056 & 3,335 & 200,109 \\
\hline Campuran 1 & 168 & 78,587 & 31,058 & $1,684 \times 10^{-3}$ & 0,015 & 0,904 & 54,222 \\
\hline Campuran 2 & 193 & 93,587 & 31,058 & $1,746 \times 10^{-3}$ & 0,016 & 0,937 & 56,207 \\
\hline Campuran 3 & 132 & 75 & 31,058 & $2,047 \times 10^{-3}$ & 0,018 & 1,099 & 65,916 \\
\hline
\end{tabular}

Laju resapan (f)

$$
\begin{gathered}
=\frac{\Delta V}{A \times \Delta t} \\
=\frac{14,5 \mathrm{~cm}^{3}}{31,058 \mathrm{~cm}^{2} \times 140,400 \text { detik }} \\
=3,325 \times 10^{-6} \mathrm{~cm} / \text { detik } \\
=0,0002 \mathrm{~cm} / \mathrm{menit} \\
=0,012 \mathrm{~cm} / \mathrm{jam}
\end{gathered}
$$

Hasil analisis laju resapan selengkapnya bisa dilihat pada Tabel 4 dan gambar 4 .

Tabel 4. Laju resapan campuran tanah dan kompos

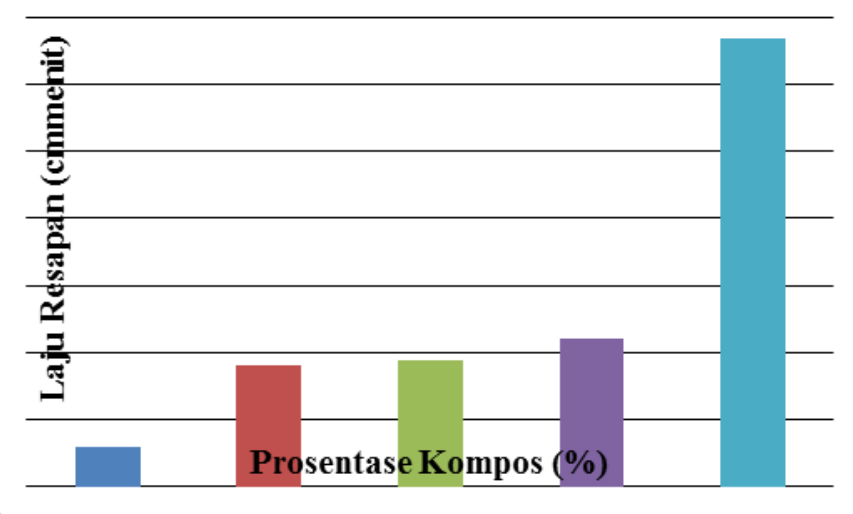

Gambar 4. Grafik hubungan antara prosentase campuran kompos dengan laju resapan tanah 
Data di atas menunjukkan bahwa dengan tanah asli genangan yang dapat meresap perjamnya adalah $0,556 \times 10^{-3} \mathrm{~m}^{3}$, jika tanah dicampurkan kompos dengan komposisi perbandingan tanah $85 \%$ : kompos $15 \%$ maka genangan yang dapat meresap perjamnya sebesar $1,684 \times 10^{-3} \mathrm{~m}^{3}$. Tanah yang dicampurkan kompos dengan komposisi perbandingan tanah $75 \%$ : kompos $25 \%$ maka genangan yang dapat meresap perjamnya sebesar $1,746 \times 10^{-3} \mathrm{~m}^{3}$. Tanah yang dicampurkan kompos dengan komposisi perbandingan tanah 65\% : kompos 35\% maka genangan yang dapat meresap perjamnya sebesar $2,047 \times 10^{-3} \mathrm{~m}^{3}$.

Diketahui dari data yang didapat dari Dinas Pekerjaan Umum Binamarga dan Pematusan Kota Surabaya Tahun 2012 bahwa tinggi genangan di daerah Kyai Tambak deres adalah $40 \mathrm{~cm}$, dengan kondisi tanah asli maka waktu yang dibutuhkan untuk meresapkan genangan setinggi $40 \mathrm{~cm}$ tersebut adalah:

waktu peresapan $=$ tinggi genangan/laju resapan

$$
\begin{aligned}
& =40 \mathrm{~cm} / 0,298 \mathrm{~cm} / \text { menit } \\
& =134 \text { menit }
\end{aligned}
$$

Jika tanah dicampurkan dengan kompos dengan komposisi tanah 85\%: kompos 15\%, maka waktu yang dibutuhkan untuk meresapkan genangan setinggi $40 \mathrm{~cm}$ tersebut adalah:

waktu peresapan $=$ tinggi genangan/laju resapan

$$
\begin{aligned}
& =40 \mathrm{~cm} / 0,904 \mathrm{~cm} / \text { menit } \\
& =44 \text { menit }
\end{aligned}
$$

Jika tanah dicampurkan dengan kompos dengan komposisi tanah 75\%: kompos 25\%, maka waktu yang dibutuhkan untuk meresapkan genangan setinggi $40 \mathrm{~cm}$ tersebut adalah:

waktu peresapan $=$ tinggi genangan/laju resapan

$$
\begin{aligned}
& =40 \mathrm{~cm} / 0,937 \mathrm{~cm} / \text { menit } \\
& =43 \text { menit }
\end{aligned}
$$

Jika tanah dicampurkan dengan kompos dengan komposisi tanah 65\%: kompos 35\%, maka waktu yang dibutuhkan untuk meresapkan genangan setinggi $40 \mathrm{~cm}$ tersebut adalah:

waktu peresapan $=$ tinggi genangan/laju resapan

$$
=40 \mathrm{~cm} / 1,099 \mathrm{~cm} / \text { menit }
$$$$
=36 \text { menit }
$$

Dari analisis diatas dapat diketahui bahwa jumlah kompos yang ditambahkan ke tanah berpengaruh terhadap peningkatan resapan tanah. Semakin banyak kompos yang ditambahkan maka semakin cepat pula waktu yang dibutuhkan air genangan untuk meresap ke dalam tanah, sehingga tinggi genangannya menjadi berkurang. Hal ini tentu berhubungan dengan porositas tanah, dimana semakin banyak kompos yang ditambahkan, porositas tanah menjadi semakin besar, sehingga genangan lebih mudah meresap ke dalam tanah.

Selain menggunakan kompos, media lain yang dapat digunakan sebagai media resapan adalah pasir dan kerikil, dimana pasir dan kerikil juga dapat meningkatkan porositas tanah sehingga memperbesar resapannya. Namun perlu dilakukan penelitian lebih lanjut mengenai media selain kompos ini.

\section{KESIMPULAN}

Dari penelitian mengenai studi campuran tanah dan kompos ini, maka dapat diperoleh kesimpulan sebagai berikut: Penambahan kompos ke dalam tanah dapat meningkatkan laju resapan dari 0,298 cm/menit menjadi: Tanah 85\%: kompos 15\% laju resapan menjadi 0,904 cm/menit. Tanah 75\%: kompos 25\% laju resapan menjadi 0,937 cm/menit. Tanah 65\%: kompos 35\% laju resapan menjadi 1,099 cm/menit. Campuran tanah dan kompos dapat mereduksi waktu yang dibutuhkan untuk meresapkan genangan setinggi $40 \mathrm{~cm}$ dari 134 menit menjadi: Tanah 85\%: kompos 15\% laju resapan menjadi 44 menit. Tanah 75\%: kompos $25 \%$ laju resapan menjadi 43 menit. Tanah 65\%: kompos 35\% laju resapan menjadi 37 menit 


\section{DAFTAR PUSTAKA}

Badan Standarisasi Nasional. (1990). SNI 03-1968-1990 Metode Pengujian tentang Analisis Saringan Agregat Halus dan Kasar. Jakarta

Badan Standarisasi Nasional. (2004). RSNI T-06-2004 tentang Tata Cara Pengukuran Laju Infiltrasi Tanah di Lapangan Menggunakan Infiltrometer Cincin Ganda. Jakarta

Das, B.M. (1988). Mekanika Tanah (Prinsip-prinsip Rekayasa Geoteknis) jilid 1. Erlangga, Jakarta

Dinas Pekerjaan Umum Bina Marga dan Pematusan Kota Surabaya. (2012). Data Banjir Kota Surabaya Tahun 2012. Surabaya.

Liu, C. (1981). Soils and Foundations. Prentice-Hall, Inc., Englewood Cliffs, New Jersey .

Murbandono, L. (2009). Membuat Kompos. Penebar Swadaya, JakartaMenteri Kesehatan Republik Indonesia. (2010). Peraturan Menteri Kesehatan Republik Indonesia Nomor 492/Menkes/Per.IV/2010 tentang Persyaratan Kualitas Air Minum. Jakarta.

Shirley. (1987). Penuntun Praktis Geoteknik dan Mekanikan Tanah (Penyelidikan Lapangan \& Laboratorium). Nova, Bandung.

Soong, T. T. and Dargush, G. F. (1997). Passive energy dissipation systems in structural engineering. John Wiley \& Sons, Chichester, England. 